\title{
Parintins: turismo e cultura
}

\section{Ângelo César Brandão Pimentel*}

Resumo: O presente texto é uma análise do Festival Folclórico de Parintins sob a ótica do turismo e as implicações decorrentes da interferência desta atividade nos aspectos socioculturais da cidade, da população e sobre o próprio Festival, além de realçar a toada como expressão musical que entrelaça história e memória.

Palavras-chave: Festival Folclórico de Parintins, turismo, cultura, toada.

Abstract: This present text is an analysis of the Parintins Folkloric Festival, emphasizing the tourist industry and all that is involved with its interference on the social and cultural life of the city, the people and the Festival, besides to show the "toada" as musical expression which mixed history with memory.

Keywords: Parintins, Folklore Festival, cultural, turism, toada.

A história nos mostra que o homem, desde o seu surgimento, é um ser Ainquieto, nômade, aventureiro, buscando conhecer novos lugares, ampliando seu espaço, suas fronteiras, seu conhecimento sobre o mundo, desvendando seus mistérios, desmistificando, quando possível, esse mundo, ou então, simplesmente, deixando-se levar pela imaginação e entregando-se a esta através de explicações sobre o desconhecido, que satisfizessem suas necessidades de convívio com esse mundo como também com seus semelhantes. Assim surgiram os mitos, as lendas e os ritos.

Essa busca incessante do homem por novos espaços fez com que, ao longo da história, os povos e suas culturas surgissem e se estabelecessem, mas tam-

*Bacharel e licenciado em Ciências Sociais pela Universidade Federal do Amazonas. 


\section{Ângelo César Brandão Pimentel}

bém desaparecessem por sucumbirem ao jugo do mais forte, como ocorreu com os Incas, Astecas, Maias e grande parte das tribos que habitavam o Brasil à época da colonização.

O termo "globalização" é novo, porém o seu significado não é muito diferente de colonização, mercantilismo e imperialismo quando usado com a ótica dos filhos de uma nação que sofreram todos os percalços que esses processos causaram àqueles que aqui habitavam quando do seu "descobrimento" e, conseqüentemente, a seus descendentes que também padecem com essa "nova ordem mundial" que, de novo, tenta ocupar espaços e impor culturas e modos de viver de acordo com o que lhe convém. O mesmo ocorreu durante o ciclo da borracha, quando se transferiu à "aldeia” (Manaus e Belém) toda a base material e tecnológica disponível na época, para transformar estes lugares em cidades urbanizadas e prontas para receberem a “civilização” que aqui se estabeleceria com o crescimento, infra-estrutura, saneamento básico, pontes, portos, com tecnologia inglesa e a reprodução em cópias de edificações francesas como boulevards, pontes de ferro, mercados, calçamentos. As últimas novidades da Inglaterra, Alemanha, França, Portugal e Nova Iorque estavam no consumo e na exibição de galerias e magazines da cidade, bancos, teatros, cinemas, jornais em várias línguas. (Marilene Corrêa, 1995). Dessa forma, a “aldeia” vira cidade, porém esse

processo de urbanização experimentado [pelas cidades de Belém e Manaus] a partir da segunda metade do século XIX não está intimamente ligado à intensificação da vida industrial em sentido restrito, como ocorre nas cidades européias e americanas, mas pela função comercial, financeira, política e cultural que desempenhará durante a fase áurea da borracha (...) a redefinição do espaço urbano, a redistribuição dos locais destinados aos serviços sanitários e o emprego de mecanismos de controle dos hábitos da população, o que tornava bastante visível a distribuição entre a área central da cidade, destinada aos ricos burgueses desodorizados e higienizados e às áreas "periféricas” destinadas à população trabalhadora pobre (Maria de Nazaré Sarges [1990], apud Marilene Corrêa, 1995).

Hoje esses processos de ocupação se configuram de forma mais sucinta, com o advento principalmente dos meios de comunicação de massa, primeiro o cinema, depois a televisão e mais recentemente a coqueluche do momento, a Internet. Com o aumento da velocidade de deslocamento tanto de cargas como de pessoas, os processos de globalização transformaram-se de tal forma que se impuseram, desapercebida e gradualmente, mudando o linguajar, o modo de vestir e de comer das populações periféricas, transfor- 
mando assim suas culturas. Vejamos alguns exemplos: merenda virou lanche e lanchonete nada mais é do que os fast-foods dos países ricos com os mesmos "sanduíches" e o mesmo refrigerante Coca-Cola. Mercado virou supermercado, mais limpo, melhor distribuído com maior variedade de produtos. O jeans está em toda parte, os shoppings centers com toda sua infra-estrutura de segurança, higiene, climatização substituem as ruas dos "centros comerciais" (que o diga o de Manaus, com suas lojas fechadas) que isolam as pessoas bem-vestidas e cheirosas dos shoppings, das suadas pessoas do centro.

\section{Parintins, cidade-festival}

Tal ocorre em Parintins durante o festival, onde os ricos ficam hospedados em iates de luxo aportados no Macurani, uma área desconhecida pela grande maioria que visita a cidade nessa época, e que fica hospedada nos barcos aportados à margem do Rio Amazonas, na frente da cidade. No Bumbódromo não é diferente, a divisão é mais marcante e acentuada. Enquanto a minoria rica se acomoda em camarotes, com serviço de bar, banheiros, etc., ou na arquibancada destinada aos "visitantes", que é paga e possui banheiro próprio, a grande maioria fica na arquibancada da "galera”, que é parte integrante da festa, pois conta pontos, é grátis, mas quem vai ao banheiro corre o risco de não conseguir voltar; refrigerante ou água, cada um leva o seu, e para conseguir lugar tem que enfrentar uma fila, no mínimo, desde as 12:00h até às 15:30h, quando são abertos os portões. Mesmo assim, esse espaço ficou ainda mais reduzido devido à construção de mais camarotes nessa arquibancada. A tendência é a "galera” sumir.

A cidade de Parintins se diferencia das demais do interior do Estado pelo fato de estar com sua frente voltada para o rio, coisa que sabe Deus por que as cidades da região, inclusive Manaus, ficam de “costas” para os rios que as banham, muito embora estes lhes sirvam de via de transporte ou fonte de vida, fornecendo o peixe como alimento, a água para saciar sua sede ou regar sua planta que ornamenta e embeleza, mas também alimenta. Parintins está integrada ao resto do mundo através dos meios de comunicação como rádio, televisão, jornais, telefonia e também pelo seu porto fluvial e aeroporto que tem capacidade para receber aviões de grande porte.

O povo parintinense é de boa índole, pacato, hospitaleiro, brincalhão, gozador, desconfiado. Para ele, todo mundo é "parente”, termo que é usado como saudação. Em relação aos visitantes, como são chamados aqueles que visitam a ilha durante o festival, existem algumas restrições quanto ao comportamento destes, ao modo como se vestem, em trajes de banho, como se 


\section{Ângelo César Brandão Pimentel}

estivessem na praia. Segundo os parintinenses, os visitantes sujam a cidade, principalmente com latas de cerveja e refrigerante, jogados nas ruas, transformando a cidade num grande bar, onde passam o dia todo se embriagando. Porém, o que mais os parintinenses reclamam é o fato de não ganharem dinheiro com o festival e ainda terem que conviver com essa desordem generalizada que toma conta da cidade ou, o que é pior, quando alguma filha engravida ou, mais grave ainda, adquire alguma doença sexualmente transmissível.

Apesar de tudo, a festa existe e, mesmo perdendo seu espaço (segundo alguns, a festa está deixando de ser dos parintinenses, o que não é verdade, pois a festa é feita por eles, e não somente para eles), a festa tomou a dimensão que tomou justamente porque os parintinenses a fazem e empregam nela toda sua emoção, dando-lhe assim esse aspecto de originalidade ou autenticidade.

\section{A tradição do boi}

É dessa forma que procuramos analisar esse fenômeno chamado "boi de Parintins", visto que os parintinenses se entregam espiritualmente, de corpo e alma, a essa festa, fazendo com que ela ganhasse características próprias e peculiares, embutidas de nuanças que refletem a concepção do mundo e da vida do caboclo. Seu apego, dedicação e fidelidade a um "brinquedo", que é o boi, para quem está de fora é de difícil compreensão, mas para o parintinense é natural e normal. Difícil talvez de explicar, mas tem sua razão de ser, pois, com o seu boi, o parintinense canta e conta a sua vida, a sua história, seu modo de pensar, de sentir e de fazer, seu cotidiano, sua festa, seu lugar, sua identidade, sua fantasia.

Como bem salientou Regina Paula Santos:

Festas e bois são falas, são linguagens. Não são objetos e, na verdade, congelados nos museus, sentem-se como condenados à morte. São coisas vivas, modos de sentir, pensar, viver e festejar. São um dos sinais de que as pessoas lançam mão para trocar entre elas o que é importante: objetos, bens, serviços, situações, poderes, símbolos, significados (apud Brandão, 1988, p. 84).

Como o fenômeno do "boi” demonstra, Parintins possui artistas, pintores, artesãos, músicos, poetas, compositores, enfim, a arte faz parte da vida parintinense e não é à toa que o "boi”, em Parintins, ganhou a dimensão que hoje tem. Esse fenômeno reflete o que o parintinense tem de mais puro, 
reflete o seu convívio com a natureza, o imaginário que a floresta e o grande rio despertam naqueles que possuem sensibilidade e transformam tudo em poesia, em festa. O parintinense retrata esse imaginário, a mitologia, o esplendor da natureza, em forma de poesia e música, em forma de folclore, através do ritual do auto do boi, transformado em espetáculo por seu povo. Essa manifestação artística ou folclórica é classificada de "folguedo como um auto” pelos estudiosos: "Em Antropologia se diz que esta classificação é a de um ponto de vista ético, científico e externa ao grupo de produtores populares do ritual” (Brandão, 1988, p. 51).

Em Parintins se discute a procedência do bumba-meu-boi, como é conhecido este auto em outras regiões, e embora não haja nada registrado, supõe-se que tenha chegado até lá através dos soldados da borracha, vindos do Maranhão. A verdade é que o boi-bumbá, ou somente "boi”, como já se tornou corriqueiro chamar, mantém o ritual e a encenação do bumba-meuboi, porém acrescido fortemente pelo personagem indígena, tanto na música quanto na parte cênica e plástica, onde são interpretadas lendas, histórias e mitos indígenas de forma muito acentuada. Enfim, Parintins deu novos elementos ao fenômeno do boi, elementos estes que reestruturaram simbolicamente esse fenômeno de forma a transformá-lo no que ele é e no que representa para essa cidade. É como escreveu Hobsbawn:

Mais interessante do nosso ponto de vista é a utilização de elementos antigos na elaboração de novas tradições inventadas para fins bastante originais. Sempre se pode encontrar, no passado de qualquer sociedade, um amplo repertório destes elementos; e sempre há uma linguagem elaborada, composta de práticas e comunicações simbólicas. Às vezes, as novas tradições podiam ser prontamente enxertadas nas velhas; outras vezes, podiam ser inventadas com empréstimos fornecidos pelos depósitos bem supridos do ritual... (1984, p. 14).

Enfim, o festival folclórico de Parintins, que começou como brincadeira, tomou as atuais dimensões por possuir essas peculiaridades inerentes ao povo parintinense. Resta saber até que ponto a festa vai resistir às transformações que já se processam, ou se vale a pena haver resistência às imposições, tais como, por exemplo, da mídia ou da indústria fonográfica, que conseguiu modificar o ritmo das toadas para um ritmo mais "acelerado", tirando das letras todo o conteúdo que estas possuem, em função de se tornarem mais comerciais, mais vendáveis, descaracterizando e, conseqüentemente, vulgarizando as toadas, em prejuízo do festival como um todo. 


\section{Ângelo César Brandão Pimentel}

Transformações existem, a cultura é dinâmica, e o próprio festival é uma prova de que ela pode e deve ser incrementada de novos elementos, desde que se mantenha a estrutura, a sua essência, e o povo parintinense soube processar transformações no auto do boi, porém mantendo toda a parte cênica do auto, seu enredo, história, etc.

\section{Cultura e turismo}

A indústria do turismo talvez não atue diretamente sobre a festa e o que ela representa, até porque a grande maioria das pessoas que visitam a ilha durante o festival provavelmente não se interessam em entender o que está sendo mostrado, e isso é uma queixa dos parintinenses que dizem que, inclusive, os próprios jurados encarregados de avaliar o festival não o entendem e sempre há quem discorde do resultado. Para a indústria, o que importa é o turista em si, como vai se sentir em relação à sua satisfação pessoal e isso inclui acomodações, alimentação, conforto, bem-estar, infra-estrutura que o lugar pode oferecer e fazer as pessoas se sentirem "em casa". Para Adyr A. B. Rodrigues (1997), essa satisfação pessoal do turista é colocada como condição básica inerente ao turismo, ou seja, a satisfação das necessidades do turista, para que este seja um “consumidor generoso e prazeroso”.

Em segundo lugar, ela observa que "deve-se pensar nos custos e benefícios que o turismo traz à população residente, ou seja, nos seus impactos econômicos, sociais, políticos e culturais”. Destes quatro itens, a nosso ver, o econômico e o político estão sendo trabalhados, enquanto o social no sentido de atender também a população local, no que diz respeito ao impacto causado por aqueles que visitam a ilha durante o festival, impacto não muito explícito, pois não é manifestado abertamente. Quanto ao aspecto cultural, teríamos que verificar até que ponto há essa preocupação por parte dos turistas, tanto em relação ao festival como também à vida cotidiana da população local.

Por último, Rodrigues lembra da necessidade da "preservação do patrimônio cultural e ambiental, sem o qual o turismo corre o risco de autodestruir-se" (grifo meu). O patrimônio existe, constituído pelo lugar, bonito, exótico e esplendoroso, com todos os mistérios e encantos que a floresta e o grande rio oferecem; pela sua gente alegre, festeira, hospitaleira e pela festa em si, que resgata uma cultura composta de mitos, ritos, lendas desse povo que faz a sua festa sem deixar de lado a sua história e repassa toda essa energia àqueles que se aventuram a conhecer esse lugar e essa festa, pois há uma interação entre público e brincantes transfigurando-se num todo, único. A música, a toada, une história e memória, sonho e realidade. 


\title{
Toada, o canto do caboclo
}

A história da ocupação da Amazônia pelos europeus sempre foi contada sob a ótica da cultura destes, vista através de um prisma que abre um leque amplo em interpretações e explicações fantasiosas, exuberantes, mitológicas, sobrenaturais, lendárias, etc. O próprio nome Amazonas é fruto desse imaginário.

\author{
... No templo das mulheres Yaci Uaruá \\ Ubá, no grande rio onisciente \\ exaltavam a natureza continente \\ a terra, a água, o fogo, a mata e o ar. \\ Guerreiras Amazonas, sua fama vem de longe, \\ atravessou o mundo \\ e veio para o rio-mar \\ com feitiço colorido no olhar \\ belezas de tangas, os guerreiros vão te amar.
}

(David Jerônimo e Ademar Azevedo).

A Ilha Tupinambarana, localizada à margem direita do Rio Amazonas, já foi chamada de Ilha Encantada em virtude da lenda que conta que, no ano de 1496, o Capitão Armendariz de Córdoba e sua tripulação, no dia 23 de abril daquele ano, à meia noite, ouviram 12 badaladas de um sino possivelmente instalado na Serra Grande, hoje Serra de Parintins. Assim nos conta Tonzinho Saunier, ele próprio com suas estórias quase uma lenda.

O nome Parintins é oriundo de Parintintim, tribo guerreira do tronco Tupi, originária do Rio Madeira, mas que passou pela ilha deixando sua marca, ao guerrear com as tribos do lugar. Parintintim ou Kawahiwa, segundo Nunes Pereira (1980:539), é o "nome que designa uma qualidade de pequenas vespas sociais, de cor avermelhada e muito irritáveis". Ainda segundo Nunes Pereira, os Parintintim eram de baixa estatura, confeccionavam cerâmica, adornavam-se com plumagens, eram tenazes e guerreavam com ferocidade tamanha que punham para correr inclusive os Mundurucu, seus maiores adversários na guerra. Possuíam os órgãos genitais muito grandes, e a liberdade sexual era deliberadamente permitida.

...Lendários guerreiros do norte cruéis caçadores da Munduruncânia armados pra grande batalha no vale sagrado da morte...

(I. Medeiros/T. Medeiros/Marlon Brandão, 2000). 


\section{Ângelo César Brandão Pimentel}

A região do baixo Amazonas, mais precisamente Parintins, possui o maior rebanho bovino do Estado, talvez por isso ele seja tão venerado e amado na região. O boi, esse animal mítico, profano, religioso, lendário sempre esteve e está presente, senão em todas, na maioria das culturas existentes. No Paleolítico, já havia registros em cavernas sobre a presença do boi e sua utilização pelo homem.

Há algum tempo se aprendia na escola sobre as utilidades desse animal, que para alguns serve como instrumento de escárnio, desprezo e crueldade, como na farra do boi, nas touradas e nos rodeios. Porém, existem aqueles que dão o merecido valor ao animal, pois, como já disse, nas antigas aulas de ciências, se aprendia que do boi tudo se aproveita, os ossos para fazer botões e enfeites, o couro para confeccionar os mais variados utensílios, a carne e até suas vísceras (miúdos) são aproveitados, o leite e seus mais variados derivados alimentícios.

A figura do boi é algo impressionante. Ele tanto transmite energia, virilidade, força, como também paz, tranqüilidade, segurança. Observar um boi no pasto, seus gestos, a maneira de levantar a cabeça para mastigar e engolir o capim, de forma serena, sempre observando à sua volta, à espera, com a certeza de que logo será abatido, porém, ele está ali para isso, para servir. Um boi na manada, deitado à sombra de frondosa árvore, na beira do Limão, do Andirá, do Macurani, na beira de um rio, ruminando, com o olhar distante, perdido no horizonte, autoritário, majestoso, dono de si e do universo, como se fosse a própria encarnação de Júpiter, que se vestiu de touro para conquistar a bela Europa, cercado de amigos, como em "Amigos do boi", de Chico da Silva:

Coroca amiga do boi

A piaçoca também

O maçarico ligeiro

Tetéo companheiro

A meu boi querem bem

A saracura vadia, fica na vigia de olho em alguém

A garça, rainha da brancura, corteja o meu boi na manada

$O$ anum amigo acompanha

Meu touro em revoada.

(Chico da Silva, 1993).

É essa a vida do boi em Parintins. 
Mas existe aquele outro, o brinquedo, o boi de pano. Aquele de olhar matreiro, de “esgueira”, dengoso. De moleque que acabou de ser pego em uma travessura. De olhar desconfiado, na expectativa de ser repreendido, mas já pronto para aprontar outra.

É esse boi que faz a festa. Festa trazida por nordestinos, mas que foi moldada e reestruturada pelo caboclo, introduzindo a sua cultura, a cultura índia e reelaborando sua forma de se apresentar, de maneira a expressar essa cultura nativa. Esse boi, brinquedo de São João, boi de Lindolfo, do Pai Francisco e Catirina, dos brincantes em volta da fogueira, nos quintais das casas, nas ruas, onde as pessoas se reuniam em torno dela e ela era o elemento que unia, pois o ato de pular fogueira criava laços mais fortes até que os de parentesco ou religioso. Assar batata, banana, milho na fogueira e oferecer a alguém, significava, de acordo com quem oferecia e quem recebia, as mais variadas interpretações. Fazer adivinhações com água esquentada na fogueira, com brasa de lenha, com a cinza, e até com fumaça, era de suma importância. Enfim, o fogo carrega uma gama muito grande de simbolismo. Como nos diz Paes Loureiro,

Nas diferentes culturas, o fogo exerceu um especial e múltiplo fascínio. É signo intermediário entre o céu e a Terra. É criação e destruição. É o rubro, o verão, o coração. É a chama ardente do amor. O fogo simboliza as paixões. Simboliza a sabedoria humana e divina, a purificação e o demoníaco. Uma língua de fogo trouxe a ciência no Pentecostes. Instrumento de Deus e do demônio. Gilbert Durand diz que: "A palavra pura, raiz de todas as purificações, significa ela própria fogo em sânscrito"... (1995, p. 247).

Esse boi de pano, brinquedo de São João que nasceu para assustar, encantar e fascinar as crianças, evoluiu, desenvolveu-se, trazendo movimentos e expressões que se aproximam da realidade e hoje encanta não somente as crianças mas também aos adultos, de todas as idades, de todos os locais do país e do exterior.

... Brinca mais, rente ao chão

E surpreende com seu corpo a multidão

Seja o sol - Em plena névoa

Que o arco-íris surgirá do seu clarão

Viva na arena os movimentos

De esplendor de um boi real

Traça no caminho a singeleza

Que afaga essa ilusão 


\section{Ângelo César Brandão Pimentel}

$\cdots$

Na evolução

Roda a fogueira

Que incendeia

Os desejos da criança

Que lhe beija

É de onde vem essa paixão.

(Tadeu Garcia, Quinta evolução, 1998).

Esse boi inspira pintores, escultores, artesãos em geral e poetas-compositores de toadas, de baladas, autores como Emerson, Maia, Tadeu Garcia e Chico da Silva, que junto com Fred Góes, compôs em versos o retrato falado do que é Parintins, com sua gente, seus costumes, sua origem, seu modo de viver,

Na Ilha Tupinambarana

Parintins que eu vou decantar...

Parintins dos Parin-tin-tins

O nome da tribo desse lugar...

No seio da mata virgem

A pureza das araras

O som do silêncio morno...

O som do silêncio... Para quem tem sensibilidade, a mata, quente e úmida, está sempre emitindo sons. Sons dispersos, alegres, distantes, tristes, solitários, melancólicos. Sons como...

O canto da ariramba

da pomba-galega, melancólico, distante do...

Barranco do rio-mar...

Que cai e é levado pelas águas do grande rio Amazonas para, lá na frente, ressurgir como bancos de areia, praias onde os tracajás, os iaçás, as tartarugas depositarão seus ovos para serem chocados.

O som rouco do remanso...

Lugares de clima quente, úmido com aquele...

Mormaço brando no ar...

Ar que carrega...

O cantar do miri-miri... 
O som do...

Mari-mari e taperebá...

Frutas que ao caírem do galho se chocam com esse ar, com outros galhos, folhas e, por fim, com a terra que os acolhe, germinando-os ou permitindo que outros seres da floresta os usem como alimento. Floresta que pulsa, que alimenta e devora, mas, também, exala...

\section{O cheiro do murici... \\ O vinho de patauá...}

Patauá, trabalhado e transformado em vinho para ser tomado puro ou com farinha. A tão mal-falada farinha de mandioca, não aceita pelos estudiosos que não entendem por que ela, tão pobre em nutrientes, está sempre presente à mesa do caboclo, esse homem discriminado, incompreendido, tachado de preguiçoso, indolente, que não produz excedentes, que se satisfaz somente com o "pouco" que a natureza lhe oferece e, por isso, só produz o suficiente para a sua (sub)existência e de sua família.

Talvez esses estudiosos falem assim por nunca terem passado um dia sequer debaixo desse sol imponente, causticante. Por nunca terem passado um dia no seio da mata quente, úmida, abafada, à espera de uma caça ou colhendo frutas, cascas, folhas para produzir alimentos ou remédios, que a sabedoria cabocla soube desenvolver a partir dos conhecimentos herdados de seus ancestrais, os índios, que sempre souberam conviver com ela, a natureza, respeitando-a como parceira, cúmplice, nessa difícil tarefa que é viver.

Essa cumplicidade em que o caboclo produz a farinha e a natureza dá...

O lambo do peixe-boi...

Para ser apreciado e deliciado com farinha ou um

Pirarucu bem assado...

Como também o tambaqui, o jaraqui, o tucunaré, o pacu, o bodó, assados ou cozidos no caldo branco, com água do Amazonas, ou do Andirá, do Limão, do Ramos. Às vezes, essa farinha também acompanha carnes, frutas como o tucumã, a banana, o vinho de patauá, de açaí, de taperebá, de buriti, etc., servida também com outra farinha, o...

Piracuí de bodó... 


\section{Ângelo César Brandão Pimentel}

Esse caboclo tem seus costumes aprendidos na tenra idade, na infância, ao longo de sua vida, aprendidos com jogos, brincadeiras, mantendo sua cultura e transmitindo-a através de festas, do folclore, em brincadeiras como a...

Manja de turma se esconde

A outra vai procurar...

Folclore que fala, interpreta entre outras, sobre...

A tribo das Andirás

E a dança do Tangará...

Esse folclore que fala sobre sua gente, seus personagens, gente que faz da ilha a cidade pitoresca, acolhedora que é, então essa...

Terra de dona Ciloca

De dona Cândida, seu Valdir, do Chico, do Emerson, do Tonzinho, do Roxinho, que reelaboraram esse folclore que vive, recria e reproduz crenças, danças, folguedos, lendas, mitos, ritos, tanto europeus como indígenas, como as...

\section{Pastoras e meu boi-bumbá...}

Boi-bumbá, que retrata de forma fantástica o dia-a-dia do caboclo, seu modo de ver e encarar a vida, seu modo de viver e conviver com a natureza, interpretando-a, sabendo assim quando e como ir...

A pesca da piraíba...

Ou a uma...

Viração de tracajá...

Vida do caboclo, que...

Roda que roda e balança meu rei,

vibra, vive, esse sonho de infância bonito

És guerreiro, és vaqueiro do boi Garantido.

(E. Maia, 1997).

E o boi, a festa, o festival se transportam e se transformam em uma nova realidade. Sem deixar de ser sonho, pois, o sonho é uma realidade possível desde que se busque e se tente conquistar essa realidade, e a nossa realidade é a do capital, do lucro, do fausto, da fama. E o caboclo que é o calo do ca- 
pitalismo, com a sua preguiça, deitado em sua rede, "escamoteando a morena”, tirando a sua sesta, não conformado, mas satisfeito com o que tem,

Rio Amazonas, teu cenário é uma beleza.

a natureza chega até se admirar

o teu caboclo tão altivo e altaneiro

para o mundo inteiro virou festa popular.

Olha já!

Meu jeito aqui escamoteando a morena, na lua serena brincando de boi-bumbá

No terreiro é festa, tarubá, manicuera

a fogueira viva, o boião já vai chegar

traz o tucupi, faz o tacacá.

Tem pacu, bodó, tem curimatá

vinho de cupu, de taperebá,

festa do caboclo destreza, índio brasileiro

Garantido é festa, é o rei desse lugar.

(E. Maia, 1993).

Enfim, a toada é isso: o canto da floresta, dos rios, das tribos dizimadas, dos costumes.

De onde vem a magia da toada?

Vem do sangue do caboclo

Vem do cheiro da cabocla

Ou das águas do grande rio

De onde vem o encanto da toada?

Vem do compasso das remadas

Vem das tribos dizimadas

Vem das cinzas das queimadas

O feitiço e a magia vêm da ilha

Tá no sangue

Tá na veia

Tá na vida.

(T. Medeiros/ I. Medeiros/ Edval Machado, 1998).

A toada é como a Amazônia, quem não a conhece, não a entende, tenta modificá-la ou moldá-la de acordo com os interesses, assim como fizeram os colonizadores, como fazem agora os capitalistas. 


\section{Referências bibliográficas}

BRANDÃO, Carlos Rodrigues (1988). O que é folclore. São Paulo: Brasiliense (Coleção Primeiros Passos).

CÉRQUA, Dom Arcângelo (1980). Clarões de fé no Médio Amazonas. Manaus: Imprensa Oficial.

ENCARTES dos CD’s da Associação Folclórica Boi-Bumbá Garantido. Anos de 1993, 1997, 1998 e 1999. Parintins.

HOBSBAWN, Eric (1984). A invenção das tradições. Rio de Janeiro: Paz e Terra.

PAES LOUREIRO, João de Jesus (1995).Cultura amazônica. Uma poética do imaginário. Belém: Cejup.

PEREIRA, Nunes (1980). Moronguetá: um Decameron indígena. Rio de Janeiro: Civilização Brasileira, vol. 2.

RODRIGUES, Adyr A. B. (Org.) (1996). Turismo e Geografia. Reflexões teóricas e enfoques regionais. São Paulo: Hucitec.

RODRIGUES, Adyr A. B. (1997). Turismo e espaço: rumo a um conhecimento transdisciplinar. São Paulo: Hucitec.

SAUNIER, Tonzinho (1989). O magnífico folclore de Parintins. Manaus: Imprensa Oficial.

SILVA, Chico da. LP Cantiga de Parintins. Polygram.

SILVA, Marilene Corrêa da (1995). Globalização na Amazônia. Texto apresentado ao Seminário Invenção da Amazônia, promovido pela Secretaria de Estado da Cultura e Turismo, Manaus (mimeo).

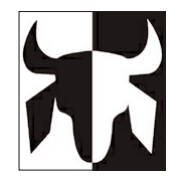

